\title{
Original Afrticle
}

\section{Microbial resistance in patients with urinary tract infections in Al-Mukalla,} Yemen

\section{Abstract}

\author{
Ahmed M. Al-Haddad ${ }^{1 *}$, Abdulla S. Bin Ghouth ${ }^{2 *}$, Mervat El-Hosseiny ${ }^{1^{*}}$
}

Background: Urinary tract infection (UTI) is an aggravating and common problem in human at sometimes during their life and may give more complications.

Objective: To project antimicrobial resistance in patients with UTI as a wide problem among cases referred to the National Center of Public Health Laboratories in Ibn-Sina Teaching Hospital in AlMukalla, Hadhramout Governorate in Yemen.

Materials and methods: From 290 cases referred from Ibn-Sina Teaching Hospital outpatients, urine samples were tested and reported in the National Center for Public Health Laboratories at the period from 2003 to 2006. Data were obtained from the records of the center (for urine examination, culture and sensitivity test) and analyzed.

Results: Among 290 cases, 147(50.7\%) were suffering from urinary tract infection. E. coli, which is the normal intestinal flora, was the most common isolate 52 (35.4\%). E. coli showed high resistance against quinolones $(84.6 \%)$ and penicillin $(78.8 \%)$ and there was no resistance against macrolides.

Conclusion: Microbial resistance strains were high, which may be due to the abuse of antibiotics.

Keywords: Hadhramout, E. coli, macrolides, quinolones.

U rinary tract infection (UTI) is the second most common infectious presentation in community practice. World wide, about 150 million people are diagnosed as urinary tract infection each year, costing the global economy about 6 billion dollars ${ }^{1}$.

Urinary tract infection may involve both the upper and lower tract or be confined only to the lower urinary tract ${ }^{2}$. The majority of Urinary tract infection can be attributed to microbial species that are members of the intestinal micro flora, the most common of which are E. coli, Klebsiella species, Enterobacter species and Proteus mirabilis ${ }^{3}$.

Urinary tract infection is often treated with different antibiotics and the extensive uses of antimicrobial agent have invariably resulted in the development of antibiotic resistance.

1 Department of Microbiology

2 Department of Community Medicine.

* College of Medicine, Hadhramout University for

Science and Technology, Yemen

Correspondence:

Email: ahmed al haddad@yahoo.com,

Mobile: +967-733251099

Office: $+967-5381279$
This in recent years has become a major problem world wide ${ }^{4}$.

There are no much information on etiology and resistance pattern of urinary tract infection in Yemen, so this study was carried out to elucidate the etiology of urinary tract infection and the antimicrobial resistance of the isolated uropathogene in patients with UTI attending outpatients clinics in Ibn-Sina teaching hospitals in Al-Mukalla city, Hadhramout Governorate (at East Yemen).

This study is important for clinicians, in order to facilitate the effective treatment and management of patient with symptoms of urinary tract infection.

\section{Materials and Methods:}

This is retrospective descriptive study performed by collecting up data from National Center for Public Health laboratories in Al-Mukalla.

The study included all cases referred from Ibn-Sina Teaching Hospital outpatients to the Center from January 2003 to December 2006 (the center stopped work for about 7 months from the $7^{\text {th }}$ September 2005 to $13^{\text {th }}$ March 
2006 due to the reconstruction of the building).

Midstream urine samples for cultures were collected from 290 cases. Each specimen was inoculated into both blood agar and MacConkey agar plates using a $0.001 \mathrm{ml}$ standard loop and incubated aerobically at $37^{\circ} \mathrm{C}$ for 24 hour, the number of colonies were counted. Urinary tract infection was defined as the culture of a single type of microorganism at a concentration of $10^{5}$ Colony Forming Unit (CFU)/ $\mathrm{ml}^{5}$.

Bacterial susceptibility for different antimicrobial agent was assessed according to Kirby-Bauer method $^{6}$, using the following antimicrobial drugs: nalidixic acid, nitrofurantoin, trimethoprim, oxalinic acid, norfloxacin, amikacin, ofloxacin, ciprofloxacin and cephalixine.

The antimicrobial drugs were classified into groups according to pharmacological classification.

\section{Results:}

In this study the total number of cases was 290, males to females ratio was 1.6:1. Urine cultures and sensitivity tests were done for all cases and out of the total screened cases there were 147 positive cultures $(50.7 \%)$, meaning urinary tract infection.

Out of the affected cases; there were 100 males (68\%) (Table1). Most of the cases aged over 50 years (93 cases; 63.3\%) especially in males $(70 \%)$. Gram negative bacilli were isolated in 124 cultures $(84.4 \%)$ while gram positive cocci were isolated only in 23 cultures $(15.6 \%)$ which were mainly Streptococcus and Staphylococcus.

Table 1: Distribution of urinary tract infections by age groups and sex.

\begin{tabular}{|c|c|c|c|}
\hline \multicolumn{4}{|c|}{ Sex (No.) } \\
\hline $\begin{array}{l}\text { Age } \\
\text { (yrs) }\end{array}$ & Male & Female & No. $(\%)$ \\
\hline $0-9$ & 2 & 6 & $8(5.4)$ \\
\hline $10-19$ & - & 1 & $1(0.7)$ \\
\hline $20-29$ & 15 & 5 & $20(13.6)$ \\
\hline $30-39$ & 9 & 10 & $19(12.9)$ \\
\hline $40-49$ & 4 & 2 & $6(4.1)$ \\
\hline$>50$ & 70 & 23 & $93(63.3)$ \\
\hline Total & 100 & 47 & $147(100)$ \\
\hline
\end{tabular}

The family of Enterobacteriaceae was isolated in $112(90.3 \%)$ cultures from all gram negative bacilli. Moreover E. coli presented the highest prevalence in the family (35.4\%), followed by Enterobacter (28\%), Citrobacter $(5.4 \%)$ and others $(7.4 \%)$ (Table2).

Table 2: Frequency distribution of of uropathogens isolated in the National Center of Public Health Laboratories in Al-Mukalla, 2003-2006

\begin{tabular}{l|c} 
Isolates & $\begin{array}{c}\text { Total } \\
\text { No. of cases (\%) }\end{array}$ \\
\hline E. coli & $52(35.4)$ \\
Enterobacter species & $41(28)$ \\
Streptococcus & $15(10.2)$ \\
Pseudomonas species & $12(8.2)$ \\
Staphylococcus & $8(5.4)$ \\
Citrobacter species & $8(5.4)$ \\
Others* & $11(7.4)$ \\
\hline Total & $147(100)$ \\
*Others include: Acinetobacter, Providencia, \\
Klebsiella and Proteus .
\end{tabular}

Regarding to antimicrobial resistance; E. coli presented high resistance to quinolones $(84.6 \%)$, followed by $(78.8 \%)$ to penicillin and by $(73.1 \%)$ to cephlosporine while no resistance case was recorded to macrolides. The same results were obtained for Enterobacter species; they presented high resistance to penicillin (80.5\%), cephalosporins $(70.7 \%)$ and quinolones $(70.7 \%)$ and there was a very small percentage resistant against macrolides (2.4\%) (Table3).

Concerning the gram positive cocci, they presented different rates of resistance to penicillin, cephalosporin, tetracycline, quinolones and macrolides while chloramphenicol was the best drug to eradicate the bacteria.

\section{Discussion:}

Urinary tract infection is a wide spread problem among population with certain variations in the rate of infections regarding age and gender. Infections in males predominate than females in contrast to other studies $^{7-9}$, this is because the target setting 
Table 3: Antimicrobial resistance to uropathogens isolated in the National Center for Public Health Laboratories in Al-Mukalla.

\begin{tabular}{l|cccccccccc} 
Antibiotics group & $\mathrm{P}$ & $\mathrm{Ceph}$ & $\mathrm{M}$ & $\mathrm{T}$ & $\mathrm{C}$ & $\mathrm{S}$ & $\mathrm{Q}$ & AG & U T D & Total \\
\hline \multicolumn{1}{c}{ Isolate } & No (\%) & No (\%) & No (\%) & No (\%) & No (\%) & No (\%) & No (\%) & No (\%) & No (\%) & No. \\
E. Coli & $41(78.8)$ & $38(73.1)$ & $0(0)$ & $26(50)$ & $1(21.2)$ & $31(59.6)$ & $44(84.6)$ & $22(42.3)$ & $10(19.2)$ & 52 \\
E. Species & $33(80.5)$ & $29(70.7)$ & $1(2.4)$ & $13(31.7)$ & $9(22)$ & $14(34.1)$ & $29(70.7)$ & $24(58.5)$ & $17(41.5)$ & 41 \\
Streptococcus & $7(46.7)$ & $9(60)$ & $6(40)$ & $8(53.3)$ & $3(20)$ & $8(53.3)$ & $15(100)$ & $8(53.3)$ & $5(33.3)$ & 15 \\
Staphylococcus & $5(62.5)$ & $4(50)$ & $3(37.5)$ & $6(75)$ & $1(12.5)$ & $4(50)$ & $5(62.5)$ & $3(37.5)$ & $2(25)$ & 8 \\
P. Species & $9(75)$ & $7(58.3)$ & $0(0)$ & $6(50)$ & $2(16.7)$ & $5(16.7)$ & $11(91.7)$ & $7(58.3)$ & $5(41.7)$ & 12 \\
C. Species & $8(100)$ & $8(100)$ & $0(0)$ & $5(62.5)$ & $4(50)$ & $6(75)$ & $6(75)$ & $5(62.5)$ & $2(25)$ & 8 \\
Others & $10(90.9)$ & $9(0)$ & 0() & $5(45.5)$ & $4(36.4)$ & $6(54.5)$ & $7(63.6)$ & $7(63.6)$ & $5(45.5)$ & 11
\end{tabular}

E. species=Enterobacter Specie. $P$. species $=$ Pseudomonas Species . C.species=Citrobacter specie

$\mathrm{P}=$ Penicillin, $\mathrm{Ceph}=$ Cephalosporins, $\mathrm{M}=$ Macrolides, $\mathrm{T}=$ Tetracycline, $\mathrm{S}=$ Sulphonamide, $\mathrm{Q}=$ Quinolones , $\mathrm{AG}=\mathrm{Aminoglyco-sides}$ $\mathrm{C}=$ Chloramphenicole UTD= Urinary Tract Disinfectants including: Nitrofurantoin $(F)$, Novabiocine (NV) and Oxalinic acid (OX) . 
for this study (In-Sina Hospital) includes medical and surgical specialties and not Gynecology/obstetric specialties; so most of patients were males.

Increasing age was associated with increase risk of urinary tract infection; the obtained results showed that most of the positive cases were from patients aged $>50$ years. This may be due to the increasing health problems during senility.

The uropathogens identified in this study were similar to many other studies conducted in different countries ${ }^{10-}{ }^{13}$. Gram negative bacilli were the most isolated organisms (84.4 $\%)$ than gram positive organism. Most of the isolated organism belonged to the family of Enterobacteriaceae (90.3 \%). E. coli presented the highest rate of isolates among this family.

Antibiotic resistance is a major problem in treating infection caused by microorganisms. The resistance to the antimicrobials has increased over the years and resistance rate vary from country to country. In our study, $E$. coli showed high resistance against quinolone $(84.6 \%)$. This may be due to the fact that this antibiotic has been widely used in treating UTI over the past decade in this region.

In this study, the resistance of E. coli to penicillin was $78.8 \%$. There were high variations in resistance to penicillins in different parts of the world; penicillin/betalactams were the best options for therapeutic treatment in Brescia (Italy) ${ }^{14}$ while ampicillin/amoxicillin are not suitable for empiric therapy of UTI in the west of Ireland, moreover ciprofloxacin is active against the majority of UTI associated with $E$. coli in West Ireland ${ }^{15}$ but it was reported that in many European countries; the susceptibility of $E$. coli isolates to pencillins was less than $60 \%{ }^{16}$.

Enterobacter species, the second common organism in this study (28\%) showed high resistance against penicillin $(80.5 \%)$ and cephalosporins $(70.7 \%)$. This high resistance was mainly due to widespread and indiscriminate use of these drugs. Higher resistance rate for most of the antibiotics used in this study may be explained by the uncontrolled consumption of these antibiotics while the low resistance of other antibiotics in our region may be due to the fact that these drugs are not widely used and exposure to these antimicrobial is limited because of their high price and limited tolerability.

\section{Conclusions:}

In our population macrolide is the most active agent against gram negative bacilli especially E. coli and Enterobacter, while although with gram positive organisms, Streptococcus and Staphylococcus a resistance rate of $40 \%$ and $37.5 \%$ respectively was seen.

Acknowledgments: We would like to thank the members of National Center for Public Health Labs in Al-Mukalla for their support especially Dr. Nadia Hassan Ba-Awom (Bacteriologist) for her assistance in data collection and Mr. Hajj Omer Al-Shuab (Manager of the central public health laboratory, Hadhramout governorate). Also we are grateful to Dr. Abu-Baker Ba-Amer, Dr.Ahmed Ba-Saba' a, Dr. Abdul Aziz AL-

Ahmadi, Dr. Sahar Qanzel and group of second year medical students in Hadhramout University who helped us in data collection.

\section{References}

1. Gonzalez CM, Schaeffer AJ. Treatment of urinary tract infections, what's old, what's new and what works. World Journal of Urology. 1999; 17:37282.

2. Sobel JD, Kaye D. urinary tract infections. In: Mandell GL., Bennett JE., Dolin R. Douglas and Bennett's. Principals and practice of infectious diseases. $5^{\text {th }}$ ed. Philadelphia: Churchill Livingstone. 2000.

3. Tannock GW. The bowel microflora an important source of urinary tract pathogens. World Journal of Urology.1999; 17: 339-44.

4. Kumar MS, Lakshmi V, Rajagopalan R. Occurrence of extended spectrum beta-lactamases among Enterobacteriaceae spp. isolated at a tertiary care institute. Indian J Med Microbial. 2006; 24(3):208-11.

5. Burnett RW, Haber MH, Hackel E et al. Clinical laboratory medicine. Williams and wilkins, Philadelphia. 1994.

6. Bauer AM, Kirby WMM, Sherris JC et al; antibiotic susceptibility testing by a standard simple disk method. American Journal of Clinical Pathology. 1966; 45:493-6.

7. Abu Shaqra Q. Occurrence and antibiotic sensitivity of Enterobacteriaceae isolated from a 
group of Jordanian patients with community acquired urinary tract infections. Cytobios. 2000; 101:15-21.

8. Neu HC; Urinary tract infections. American Journal of Medicine. 1992; 92: 63S-70S.

9. Sobel JD, Kaye D. Host factors in the pathogenesis of urinary tract infections. American Journal of Medicine. 1984; 76: 122-30.

10. Escolano Vizcaino M, Garcia J F, Caballero Sanchez-Robles $\mathrm{L}$ et al. Infecciones de vias urinarias en atencion primaria: germenes predominantes y su sensibilidad antibiotica (urinary tract infections in primary care: predominant microbes and their antibiotic sensitivity.) Aten Primaria, 1989; 6:165-8.

11. Barrett SP, Savage MA, Rebec MP et al. Antibiotic sensitivity of bacteria associated with community acquired urinary tract infection in Britain. Journal of Antimicrobial Chemotherapy, 1999; 44: 359-65.

12. Urassa WK, Mwakagile D, Mohammed K, et al. Susceptibility pattern of uropathogenic gram negative bacilli to antimicrobial chemotherapeutic agents in a National Hospital in Dar es Salaam. East African Medical Journal, 1997; 74: 162-5.

13. Khalifa K, Ali MF, Abo el Ela $\mathrm{O}$ et al. Retrospective two-year study of urinary tract infection in the Ismailia area of Egypt. Chemioterapia, 1987; 6:500-2.

14. De Francesco MA, Ravizzola G, Peroni L et al. Urinary tract infections in Brescia, Italy: etiology and uropathogens and antimicrobial resistance of common pathogens. Med Sci Monit. 2007; 13 (6):136-44

15. Chulain MN, Murray AM, Corbett-Feeney G et al. Antimicrobial resistance in E. coli associated with urinary tract infection in the west of Ireland. Ir J Med Sci. 2005; 174(4): 6-9

16. Fluit AC, Jones ME, Schmitz FJ et al. Antimicrobial resiatance among urinary tract infection (UTI) isolates in Europe: results from SENTRY antimicrobial surveillance program 1997. Antonie Van Leewehoek. 2000; 77(2): 147-52. 